\title{
Bariatric Surgery
}

National Cancer Institute

\section{Source}

National Cancer Institute. Bariatric Surgery. NCI Thesaurus. Code C84399.

Surgery performed in morbidly obese patients to help promote weight loss. The procedure aims at the reduction of the stomach size and it is usually achieved either with the implantation of a medical device or the removal of part of the stomach. 